\title{
Comparative analysis of functional changes indicators in the body of students with different teaching of physical culture lessons
}

\author{
Andrey Orlov*, Olga Kolesnikova, Marina Schneider \\ Chuvash State University named after I. N. Ulyanov, 428015, Cheboksary, Russia,
}

\begin{abstract}
Based on the position of psychological theory of activity, the question of the need to improve the functional state of students in universities is actualized. On the basis of the ascertaining experiment, the most informative functional test was identified, which characterizes the adaptive mechanisms of the organism. Taking into account the practice of introducing extracurricular activities into physical education of university students, a comparative analysis of the index of functional changes in the organism of students engaged in different ratios of educational process organization forms is carried out.
\end{abstract}

\section{Introduction}

The ongoing reform of higher education and the introduction of new educational standards lead to increased intensification of the educational process. As a result, the requirements to the adaptive capabilities of the body of university students are increasing [1, 2].

According to the statement of the psychological theory of activity, productivity, regardless of the level of its organization, is largely determined by the formation of psychophysical functions [3], the manifestation of which directly depends on the functional state of the subject of activity. It follows from this that improving the level of functional state of university students should be among the priorities of higher education reform, since only a comprehensive solution will allow to obtain the necessary synergetic educational effect.

Currently, many universities apply new approaches to the organization of physical education of students. It is often proposed to implement a personality-oriented approach based on the independent choice by each student of the most attractive types of physical activity. As a result, within the framework of expanding the forms of organizing training sessions, the total number of hours in physical culture is redistributed in equal proportions between classroom and extracurricular (independent) classes. It is assumed that this will help to increase the physical activity of students and thereby increase their adaptive capabilities.

\section{Materials and methods}

In connection with the need to increase the functional capabilities of university students, and the practice of introducing various educational programs in physical culture, the purpose of our research is formulated as follows - to carry out a comparative analysis of functional changes in the organism of university students with a different ratio of physical education classes organizing forms.

\footnotetext{
${ }^{*}$ Corresponding author: san-04@ rambler.ru
} 
In accordance with the chosen goal, the object of the research is the functional state of students, and the subject of the research is the dynamics of functional changes index indicators in students with different proportions of physical culture and sports lessons organizing forms.

In the context of the designated research goal, its object and subject, the following tasks were formulated:

- to determine the most informative and acceptable functional test in university students' physical education practice, which characterizes the level of their adaptive capabilities;

- to carry out a comparative analysis of students' functional state indicators dynamics with a different ratio of physical culture training sessions organization forms.

The formulated research tasks determined the choice of its methods - analysis and generalization of scientific and methodological literature data, methods of mathematical statistics, interpretation of experimental data. During mathematical processing of experimental data, the arithmetic mean $(\mathrm{M})$, the error of the arithmetic mean $( \pm \mathrm{m})$, the standard deviation $(\sigma)$, the coefficient of variation (CV), and the correlation of experimental data in accordance with the law of normal distribution $(\mathrm{f}(\mathrm{x}))$ were calculated. The statistical significance of the data obtained was determined by calculating the Student's t-test with a significance level of $\mathrm{P}<0.05$. During the experiment, the following parameters were determined: passport age of the subjects; body weight and length; vital capacity of the lungs; heart rate and blood pressure, determined by the OMRON M2 Basic electronic tonometer (HEM 7121-RU). The study was conducted in compliance with the necessary ethical standards based on the Helsinki Declaration. Before starting the test, the subjects were informed about its procedure, after which they were asked for official consent to data processing. All measurements were carried out in the introductory part of physical culture training session.

Experimental work was carried out on the basis of the Department of Physical Culture and Sports of the FSBEI HE "Chuvash State University named after I.N. Ulyanov ". 147 female students of 1-3 years of chemical-pharmaceutical faculty, faculty of foreign languages, Russian and Chuvash philology and journalism took part in the research. Three experimental groups were formed from the number of students: 1st group - 1st year students $(\mathrm{n}=46)$; 2nd group 2nd year students $(n=68)$; 3rd group - 3rd year students $(n=33)$. During the period of the experiment, 64-72 academic hours were provided in the experimental groups, and in the discipline "Physical culture and sports" in the 1st year and "Elective disciplines (modules) in physical culture and sports" in the 2nd and 3rd years. At the same time, the 1st year students were scheduled for 16 hours of lecture and classroom practical classes, as well as 38 hours of independent (extracurricular) classes. In the 2nd experimental group, 32 academic hours were planned for classroom and extracurricular activities. For 3rd year students, all 64 academic hours were devoted to classroom practical lessons.

\section{Results and discussion}

As it follows from the review of scientific and methodological literature in the practice of physical education, to determine the level of the functional state of the trainees, a variety of functional tests (tests) are used and specific indices are calculated. Their use makes it possible to assess the general condition of the organism, its reserve capabilities, and the peculiarities of adaptation of various systems. A number of physiological constants are used as recorded indicators, for which special measuring equipment (electrocardiograph, gas analyzer, etc.) is used, and the data obtained are correlated with a certain scale [4]. The most famous test is the PWC170 test, which is widely used in the practice of sports training [5, 6]. Nevertheless, its use in physical education of students is very difficult, and not only in view of the need to use a bicycle ergometer, but mainly because of the relative length of the testing procedure.

Among the "operational" tests such as Stange's Probe, Genchi's Probe, Romberg's Probe, Yarotsky's Probe, Letunov's Probe, Quetelet Index, Robinson's Index, etc. can be distinguished. 
However, as a rule, they reflect the state of individual physiological systems. When studying the adaptive capabilities of the organism as a whole, the Skibinsky Index (IS) is often calculated, which characterizes the functional reserves of the cardiovascular and respiratory systems, and the Index of functional changes by R.M. Baevsky (IFC), allowing to assess the level of the circulatory system functioning, as well as the state of adaptive mechanisms is tested [7]. Their calculation does not require the use of complex measuring equipment and a lot of time when taking the initial data. Their distinctive feature is their efficiency in calculating test results, for example, IS is calculated by formula 1, and IFC by formula 2 .

$$
I S=\frac{0.01 V C x B H T}{H R}
$$

where: VC - vital capacity of the lungs ( $\mathrm{ml}$ ), BHT - breath holding time (sec), HR - heart rate (beats / min)

$$
\boldsymbol{I F C}=0.011 \mathrm{HR}+0.014 \mathbf{S B P}+0.008 \mathrm{DBP}+0.014 \boldsymbol{A}+0.009 \boldsymbol{B W}-0.009 \boldsymbol{B L}-0.27
$$

where: HR - heart rate (beats / min), SBP - systolic blood pressure ( $\mathrm{mm} \mathrm{Hg}$ ), DBP - diastolic blood pressure ( $\mathrm{mm} \mathrm{Hg}$ ), A - passport age (full years), BW - body weight ( $\mathrm{kg}$ ); $B L$ - body length (cm), 0.27 independent coefficient.

Undoubtedly, functional indices identified on the basis of scientific and methodological literature analysis suggest the determination of the most informative one among them. For this reason, in the first decade of September 2019, we conducted a stating experiment to test them. As a result of calculating the coefficient of variation in the measured indicators, it was revealed that the measure of variance in the IS indicators is significantly higher in comparison with the scatter of the data in the IFC indicators $(47.35 \%$ versus $15.83 \%)$. Thus, IFC is more informative in comparison with IS, and can be recommended for wide application in the practice of physical education of university students.

The IFC indices of 1-3 year students of the ascertaining experiment were taken by us as the initial intragroup values for further research. It should be noted that the IFC value is inversely proportional to the adaptation potential, i.e. the higher the adaptive capacity, the lower the value of the IFC. In this case, the organism functional state gradation is determined in accordance with a special scale [8].

As follows from the data presented in table 1, the initial arithmetic mean values of the IFC of female students of different years differ insignificantly ( $P>0.05)$, and are within the limits of "satisfactory adaptation". The confirmation of the relative homogeneity of research subjects' composition can be the distribution of IFC initial parameters of 1-3 year students in accordance with the law of normal distribution. Figure 1 illustrates that the Gaussian curves of experimental groups parameters are practically identical.

Table 1. Ratio of initial and final IFC indicators of students of ChSU named after I. N.

\begin{tabular}{|c|c|c|c|c|}
\hline Indicators & $\mathrm{n}$ & initial & final & $P_{1}$ \\
\hline 1 year & 46 & $2,141 \pm 0,048$ & $2,240 \pm 0,056$ & $>0,05$ \\
\hline 2 year & 68 & $2,165 \pm 0,042$ & $2,131 \pm 0,044$ & $>0,05$ \\
\hline \multirow[t]{4}{*}{3 year } & 33 & $2,129 \pm 0,058$ & $2,116 \pm 0,048$ & $>0,05$ \\
\hline & $P_{2}$ & $>0,05$ & $>0,05$ & \\
\hline & $P_{3}$ & $>0,05$ & $>0,05$ & \\
\hline & $P_{4}$ & $>0,05$ & $<0,05$ & \\
\hline
\end{tabular}
Ulyanov, ( $\mathrm{M} \pm \mathrm{m}$, points)

where: $\quad P_{1} \quad-$ significance of differences between initial and final indicators

$P_{2} \quad$ - significance of differences between the indicators of the 1st and 2nd year students

$P_{3} \quad$ - significance of differences between the indicators of the 2 nd and $3 \mathrm{rd}$ year students

$P_{4} \quad$ - significance of differences between the indicators of the 1st and 3rd year students

When analyzing the final IFC indicators, it was found that during the experiment, the dome of the Gauss curve of the 3rd year students is slightly stretched vertically, which indicates a decrease of the spread in measured indicators. At the same time, among the 1st and 2nd year 
students, it stretches horizontally, stating an increase in the dispersion measure of experimental data obtained (Fig. 2). Moreover, if the arithmetic mean value of the IFC of the 2nd year students slightly improves in comparison with the initial indicators, then the 1st year students showed negative dynamics in the measured indicators (Table 1). At the same time, the dome expansion of the Gaussian curve of the 2 nd experimental group along the abscissa indicates an increase in the scatter of data and allows us to conclude that the improvement in the arithmetic mean value of this group is due to an increase in the adaptive capabilities of its individual participants. We assume that these students were engaged in physical exercises on their own, while the other part of female students ignored extracurricular activities, which led to an increase in the scatter of the data. Taking into account the change in the domes of the Gauss curve of the 1st and 2nd year students, we can talk about a tendency to deterioration of adaptive capabilities in these experimental groups, while in the indicators of the 3rd year students there is a positive dynamics in the measured indicators. Moreover, in comparison with the final indicators of the students, the differences are statistically significant (Table 1).

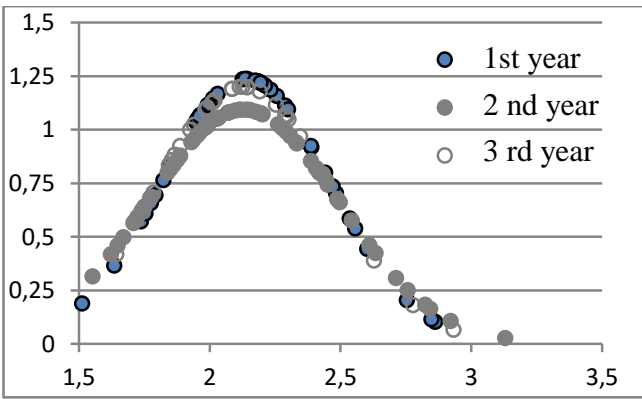

Fig. 1. Distribution of initial IFC indicators in accordance with the Gauss curve.

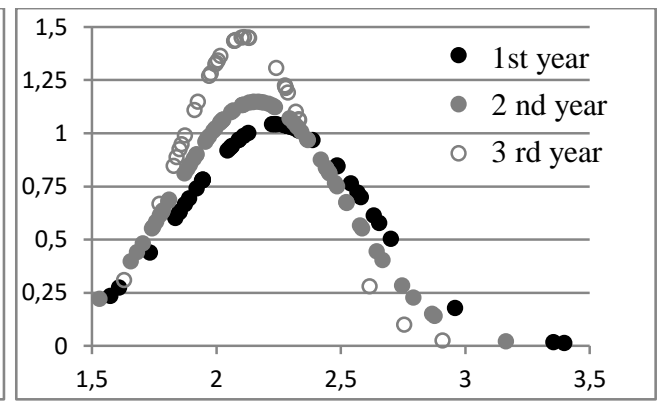

Fig. 2. Distribution of final IFC indicators in accordance with the Gauss curve.

The experimental data obtained allow us to say that, on the one hand, at the present stage of higher education development, the introduction of extracurricular forms of physical culture classes into the educational process does not ensure the implementation of personality-oriented physical education and does not contribute to an increase in students' physical culture activity. This can be explained within the framework of the "mechanism for objectifying the need", as a result of which the motive for activity is formed [3]. As evidenced by many years of pedagogical experience, the overwhelming majority of student youth has a subjective need for physical health satisfied, which does not induce them to increase their physical activity. On the other hand, the interpretation of the research results in the framework of the philosophical category "condition", understood as the relation of the subject to the surrounding phenomena and without which it can not exist [9], allows us to conclude that an important condition for improving the adaptive capabilities of University students is an increase in the number of classroom practical classes in physical culture. They, providing an increase in adaptive capabilities of the body, are a prerequisite for increasing the productivity of educational activities, allowing you to cope successfully with an increasing intellectual load.

\section{Conclusions}

The study made it possible to formulate a number of conclusions:

1. On the basis of scientific and methodological literature analysis and the conducted ascertaining experiment, it was revealed that the most informative test, which makes it possible to judge the functional state of university students, is the index of functional changes. When calculating it, the use of complex measuring equipment is not required, it is quite prompt in 
calculating the results, which together allows us to recommend it for widespread use in the practice of physical education of university students.

2. Comparative analysis of functional changes index indicators dynamics in students involved in physical culture with a different ratio of training sessions organization forms, allows us to assert that at the present stage of higher education development, the introduction of independent classes is not justified, as it provokes a decrease in the adaptive capabilities of students' organism. As a result, conditions are not created to increase the effectiveness of educational process. In order to create conditions for increasing the productivity of university students' educational activities, we consider it reasonable to conduct a greater number of classroom practical physical culture lessons at all training courses.

\section{References}

1. N.V. Altynova, V.K. Talantseva, Proceedings of the First International Volga Region Conference on Economics, Humanities and Sports (FICEHS 2019). Advances in Economics, Business and Management Research (Atlantis Press, Paris, 114, 624-628, 2020)

2. V.K. Talantseva, N.V. Altynova, N.N. Pyanzina, Theory and practice of physical culture and sport, 4 , 45-48 (2020)

3. A.S. Kuznetsov, Z.M. Kuznetsova, Russian Journal of Physical Education and Sport, 14(4), 5-7 (2019). DOI: 10.14526/2070-4798-2019-14-4-5-7

4. Functional tests for assessing the state of the organism. URL https://medbe.ru/materials/raznoe-vreabilitatsii-i-adaptatsii/funktsionalnye-proby-dlya-otsenki-sostoyaniya-organizma

5. A.I. Pyanzin A.I., Science and sports: current trends, 1(2), 33-45 (2014)

6. A.I. Pyanzin, A.A. Kuzmin, N.N. Pyanzina, Pedagogico-psychological and medico-biological problems of physical culture and sport, 1(30), 130-136 (2014)

7. A.V. Lavrikov, Young scientist, 4, 305-307 (2014)

8. Determination of functional changes. URL: index/https://studopedia.ru/17_6204_zadanie-opredelenie-indeksa-unktsionalnih-izmeneniy.html

9. I.T. Frolov, Philosophical dictionary (M., 1991) 